\title{
Multicriteria FMECA Based Decision-Making for Aluminium Wire Process Rolling Mill through COPRAS-G
}

\author{
Nilesh Pancholi ${ }^{1}$ and M. G. Bhatt ${ }^{2}$ \\ ${ }^{1}$ Gujarat Technological University, Visat-Gandhinagar Highway, Chandkheda, Ahmedabad, Gujarat 382424, India \\ ${ }^{2}$ Shantilal Shah Engineering College, Post: Vartej, Sidsar, Bhavnagar, Gujarat 364060, India \\ Correspondence should be addressed to Nilesh Pancholi; nhpancholi@gmail.com
}

Received 4 March 2016; Revised 21 April 2016; Accepted 12 June 2016

Academic Editor: Kwai S. Chin

Copyright (C) 2016 N. Pancholi and M. G. Bhatt. This is an open access article distributed under the Creative Commons Attribution License, which permits unrestricted use, distribution, and reproduction in any medium, provided the original work is properly cited.

\begin{abstract}
This paper presents a multifactor decision-making approach based on "grey-complex proportional assessment (COPRAS-G) method" in a view to overcome the limitations of Failure Mode Effect and Criticality Analysis (FMECA). In this model, the scores against each failure mode are expressed in grey number instead of crisp values to evaluate the criticalities of the failure modes without uncertainty. The suggested study is carried out to identify the weights of major failure causes for bearings, gears, and shafts of aluminium wire rolling mill plant. The primary findings of the paper are that sudden impact on the rolls seems to be most critical failure cause and loss of power seems to be least critical failure cause. It is suggested to modify the current control practices with proper maintenance strategy based on achieved maintainability criticality index (MCI) for different failure causes. The outcome of study will be helpful in deriving optimized maintenance plan to maximize the performance of process industry.
\end{abstract}

\section{Introduction}

The reliability and maintenance engineering is important to maintenance practitioners and reliability engineers to keep the system in a state of readiness. Moreover, it helps to identify the condition based faults, compare possible failure patterns, and maximize effectiveness in maintenance plan. There are many techniques available for planning maintenance activities of process industries. Traditional Failure Mode Effect and Criticality Analysis (FMECA) has proved to be prominence tool among maintenance personnel, where failure modes are ranked on risk priority number (RPN), which is the product of chances of failure (C), degree of detectability (D), and degree of severity (S) to prioritize the maintenance activities.

Traditional FMECA is a widely accepted methodology for prioritizing failure modes; however, it has some limitations. It does not cover the interdependency of different failure modes and their effects. It considers only limited criteria like $\mathrm{C}, \mathrm{D}$, and $\mathrm{S}$ and does not cover some important criteria like maintainability (M), spare parts availability (SP), economic safety (ES), economic cost (EC), and so forth which may also influence the failure modes. Moreover, same importance will be given to $\mathrm{C}, \mathrm{D}$, and $\mathrm{S}$ ignoring their relative importance and even small variation in the value of $\mathrm{C}$ or $\mathrm{D}$ or $\mathrm{S}$ may change the value of RPN significantly due to multiplication rule.

It has been observed that past researchers have undergone various modifications for improving FMECA to overcome these drawbacks for different processing units. Sahoo et al. [1] show that failure modes, effects, and critique analysis (FMECA) is an integral part of the technical design of maintenance and it represents a strong tool to evaluate and improve system reliability and therefore reduces costs associated with maintenance that is used in a wide range of industry. Some researchers [2-5] incorporated a new factor called operating conditions in the field of power plant. Anish et al. [5] presented a multifactor decision-making approach for prioritizing failure modes for paper industry as an alternative using TOPSIS. Braglia et al. $[6,7]$ presented fuzzy TOPSIS and Xu et al. [8] presented fussy assessment based FMEA for engine system. Gargama and Chaturvedi [9] introduced fuzzy RPN applying level sets where the three risk factors are expressed into fuzzy linguistic variables. Adhikary et al. [10] presented multicriteria FMECA for coal-fired thermal power station using COPRAS-G method. Zhang [11] presented integration 
of both subjective weights and objective weights to avoid failure modes from being underestimated or overestimated based on fuzzy TOPSIS to get the closeness coefficient for each failure mode. Chanamool and Naenna [12] highlight the importance of fuzzy FMEA for prioritization and assessment of failures that likely occur in the working process of an emergency department of hospitals. Liu et al. [13] presented a novel approach for FMEA based on combination weighting and fuzzy VIKOR method where integration of fuzzy analytic hierarchy process (AHP) and entropy method is applied for risk factor weighting in this proposed approach to deal with the uncertainty and vagueness from humans' subjective perception and experience in risk evaluation process.

It has been observed that previous researchers did not consider COPRAS-G based multicriteria decision-making approach to process industries like aluminium wire rolling mill. In this paper COPRAS-G, a multicriteria decisionmaking tool, is applied to model FMECA in lieu of the traditional multiplication rule of the criticality factors.

\section{COPRAS-G Methodology}

The concept of grey number was basically derived from grey theory, which deals with the decisions of uncertainty experienced in real-world environment [14-19]. The grey number is having upper and/or lower limits whose exact value is unknown but the interval within which the value falls is known [15-17]. Hwang and Yoon, 1981 [20], highlight importance of multicriteria decision-making (MCDM) where multiple and conflicting criteria are under consideration in different areas like personal, public, academic, or business contents.

The COPRAS-G method for criticality evaluation of failure modes is expressed through the following steps [1517]:

(1) Select the set of various criteria and failure modes and arrange them along the columns and the rows, respectively, in the decision matrix.

(2) Construct the decision-making matrix $X$ which shows the criteria ranking in grey number intervals:

$X=\left[x_{i j} ; y_{i j}\right]=\left[\begin{array}{ccc}{\left[x_{11} ; y_{11}\right]} & \cdots & {\left[x_{1 n} ; y_{1 n}\right]} \\ \vdots & \ddots & \vdots \\ {\left[x_{m 1} ; y_{m 1}\right]} & \cdots & {\left[x_{m n} ; y_{m n}\right]}\end{array}\right]$,

where $x_{i j}$ is the lower value and $y_{i j}$ is the upper value of the interval. $i=1,2, \ldots, m$ which represents the failure modes along the row and $j=1,2, \ldots, n$ which represents the criteria along the column in decision matrix.

(3) Normalize the decision matrix $X$, as follows:

$$
\begin{aligned}
x 1_{i j} & =\frac{x_{i j}}{(1 / 2)\left(\sum_{j=1}^{n} x_{i j}+\sum_{j=1}^{n} y_{i j}\right)}, \\
y 1_{i j} & =\frac{y_{i j}}{(1 / 2)\left(\sum_{j=1}^{n} x_{i j}+\sum_{j=1}^{n} y_{i j}\right)} .
\end{aligned}
$$

Normalized decision matrix $X 1$ is as follows:

$$
X 1=\left[\begin{array}{ccc}
{\left[x 1_{11} ; y 1_{11}\right]} & \cdots & {\left[x 1_{1 n} ; y 1_{1 n}\right]} \\
\vdots & \ddots & \vdots \\
{\left[x 1_{m 1} ; y 1_{m 1}\right]} & \cdots & {\left[x 1_{m n} ; y 1_{m n}\right]}
\end{array}\right] .
$$

(4) Calculate weight of each criterion based on Shannon's entropy concept where initially we have to calculate entropy $e_{j}$ and from it weight $w_{j}$ for $j$ th criteria as follows:

$$
\begin{aligned}
& e_{x_{j}}=-\frac{1}{\ln m} \sum_{i=1}^{m} x_{i j} \ln x_{i j}, \\
& e_{y_{j}}=-\frac{1}{\ln m} \sum_{i=1}^{m} y_{i j} \ln y_{i j}, \\
& w_{x_{j}}=\frac{1-e_{x_{j}}}{\sum_{j=1}^{n}\left(1-e_{x_{j}}\right)}, \\
& w_{y_{j}}=\frac{1-e_{y_{j}}}{\sum_{j=1}^{n}\left(1-e_{y_{j}}\right)} .
\end{aligned}
$$

(5) Determine weighted normalized matrix as per the following equations:

$$
\begin{aligned}
& x 2_{i j}=x 1_{i j} \cdot w_{i j}, \\
& y 2_{i j}=y 1_{i j} \cdot w_{i j} .
\end{aligned}
$$

Weighted normalized decision matrix $X 2$ is as follows:

$$
X 2=\left[\begin{array}{ccc}
{\left[x 2_{11} ; y 2_{11}\right]} & \cdots & {\left[x 2_{1 n} ; y 2_{1 n}\right]} \\
\vdots & \ddots & \vdots \\
{\left[x 2_{m 1} ; y 2_{m 1}\right]} & \cdots & {\left[x 2_{m n} ; y 2_{m n}\right]}
\end{array}\right] .
$$

(6) Calculate the weighted mean normalized sums $P_{i}$ for beneficial criteria whose larger values are preferable and $R_{i}$ for nonbeneficial criteria whose smaller values are preferable as follows:

$$
\begin{aligned}
& P_{i}=-\frac{1}{2} \sum_{j=1}^{k}\left(x 2_{i j}+y 2_{i j}\right), \\
& R_{i}=-\frac{1}{2} \sum_{j=k+1}^{k}\left(x 2_{i j}+y 2_{i j}\right),
\end{aligned}
$$

where $i=1,2, \ldots, m$, " $k$ " is the number of beneficial criteria, and $(m-k)$ is the number of nonbeneficial criteria. All the beneficial criteria are placed in the decision-making matrix first and then the nonbeneficial criteria are placed. 


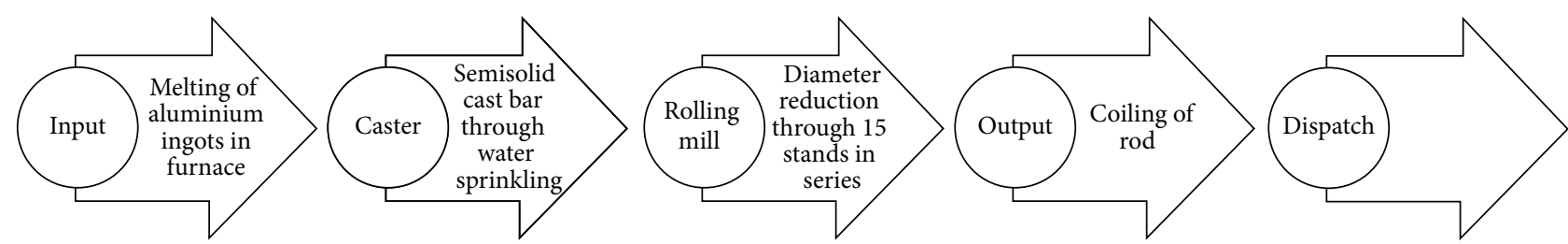

FIgURE 1: Layout of aluminium wire rolling mill process flow.

(7) Calculate the relative significance/weight MCI of each alternative as follows:

$\mathrm{MCI}=P_{i}+\frac{R_{\min } \sum_{i=1}^{m} R_{i}}{R_{i} \sum_{i=1}^{m}\left(R_{\min } / R_{i}\right)}=P_{i}+\frac{\sum_{i=1}^{m} R_{i}}{R_{i} \sum_{i=1}^{m}\left(1 / R_{i}\right)}$,

where $R_{\min }$ is the minimum value of all weighted mean normalized sums " $R_{i}$ " of nonbeneficial criteria.

The criticality ranks (priorities) of alternatives are ranked according to the value of $\mathrm{MCI}$ in increasing order; that is, larger value of MCI is having higher priority than other alternatives. $\mathrm{MCI}_{\max }$ is the maximum value of relative significance/weight among all alternatives.

(8) Calculate the degree of unity in percentage (\%) contribution $C_{i}$ for $i$ th failure cause and assign rank based on value of $\mathrm{MCI}$ :

$$
C_{i}=\frac{\mathrm{MCI}_{i}}{\mathrm{MCI}_{\max }} * 100,
$$

where $\mathrm{MCI}_{\max }$ is the maximum value of relative significance/weight among all alternatives.

\section{Case Study}

3.1. Introduction. The proposed model is applied to the aluminium wire rolling mill processing plant situated in Gujarat, India. The detailed layout of process is given in Figure 1. The aluminium wire is produced through Properzi Process where solid aluminium bar of $40 \mathrm{~mm}$ is fed into stands to gradually reduce diameter to $6 \mathrm{~mm}$ rod through fifteen stands in series. At each stand diameter of rod decreases by about $15-20 \%$. It is concluded that bearings, gears, and primary and secondary shafts are identified as most critical components based on historical comprehensive failure and repair data.

To decide the score for each individual failure mode for every process input of critical components, the following methods are used:

(i) Historical failure data which gives comprehensive behavioral study of failure pattern of critical components.

(ii) Questionnaires to floor operators, managers, and maintenance personnel.

The score for chances of failure, detectability, maintainability, spare parts, economic safety, and economic cost is ranked as per Tables 1, 2, 3, 4, 5, and 6, respectively.
TABLE 1: Scores for chance of failure (C).

\begin{tabular}{lcc}
\hline Occurrence & \multicolumn{1}{c}{ MTBF } & Score \\
\hline Almost never & More than three years & 1 \\
Very rare & Once every 2-3 years & 2 \\
Rare & Once every 1-2 years & 3 \\
Very low & Once every 11-12 months & 4 \\
Low & Once every 9-10 months & 5 \\
Medium & Once every 7-8 months & 6 \\
Moderate high & Once every 5-6 months & 7 \\
High & Once every 3-4 months & 8 \\
Very high & Once every 1-2 months & 9 \\
Extremely high & Less than 1 month & 10 \\
\hline
\end{tabular}

TABLE 2: Scores for detection of failure (D).

\begin{tabular}{lcc}
\hline $\begin{array}{l}\text { Chances of } \\
\text { detection }\end{array}$ & $\begin{array}{c}\text { Likelihood of } \\
\text { nondetection (\%) }\end{array}$ & Score \\
\hline Immediate & $<10$ & 1 \\
Best & 10 to 20 & 2 \\
Better & 21 to 30 & 3 \\
Good & 31 to 40 & 4 \\
Easy & 41 to 50 & 5 \\
Occasional & 51 to 60 & 6 \\
Late & 61 to 70 & 7 \\
Difficult & 71 to 80 & 8 \\
Very difficult & 81 to 90 & 9 \\
Impossible & 91 to 100 & 10 \\
\hline
\end{tabular}

3.2. Importance of Use of COPRAS-G. During brainstorming session, maintenance personnel score a criticality factor into different criticality levels so it is challenging to do criticality analysis of failure modes accurately. Hence this practical difficulty can be solved by expressing the scores of a criticality factor in an interval (grey number) instead of certain and exact value (white number). In this problem, COPRASG method, a multifactor decision-making tool, is used by expressing criticality factors with grey numbers in lieu of the traditional multiplication rule. The main idea of COPRAS$\mathrm{G}$ method is to express the criteria values in intervals, which comes from real situation of decision-making.

3.3. Failure Mode Effect and Criticality Analysis with Assignment of Score in Grey Number Range. The potential failure modes, their causes, and failure effect of bearings, gears, 
TABLE 3: Scores for maintainability (M).

\begin{tabular}{lcc}
\hline Maintainability scope & Criteria for measure & Score \\
\hline Extremely high & $<10$ & 1 \\
Very high & 10 to 20 & 2 \\
High & 21 to 30 & 3 \\
Moderate high & 31 to 40 & 4 \\
Medium & 41 to 50 & 5 \\
Low & 51 to 60 & 6 \\
Very low & 61 to 70 & 7 \\
Rare & 71 to 80 & 8 \\
Very rare & 81 to 90 & 9 \\
Almost nil & 91 to 100 & 10 \\
\hline
\end{tabular}

TABLE 4: Scores for spare parts (SP).

\begin{tabular}{lc}
\hline Criteria for availability and requirement & Score \\
\hline Easily available \& desirable & 1 \\
Easily available \& essential & 2 \\
Easily available \& very essential & 3 \\
Hard to procure but desirable & 4 \\
Hard to procure but essential & 5 \\
Hard to procure but very essential & 6 \\
Scarce and desirable & 7 \\
Scarce and essential & 8 \\
Scarce and very essential & 9 \\
Impossible and urgent & 10 \\
\hline
\end{tabular}

and primary and secondary shafts are generated through the root cause analysis method. The scores for chances of failure (C), degree of detectability (D), degree of maintainability (M), spare parts (SP), economic safety (ES), and economic cost (EC) for various failure causes are ranked on scale of 1-10 as per concept of grey number range in $\left[x_{i j} ; y_{i j}\right]$ based on Tables 1-6, where $x_{i j}$ is the lower value and $y_{i j}$ is the upper value of the interval as reflected in Table 7. The scales of 1 to 10 signify from least to most consideration of impact of criteria and are assigned on basis of questionnaires and brainstorming session to floor operators, shop floor managers, and maintenance personnel for various individual failure causes ( $\mathrm{C} 1$ to $\mathrm{C} 14)$.

\section{Results and Discussion}

Table 8 shows the relative significance/weight of each alternative MCI and the degree of unity in percentage (\%) contribution $\left(C_{i}\right)$ for $i$ th failure cause which is derived as per COPRAS-G methodology discussed in Section 2.

It has been observed from Table 8 that design defects and bearing dimension not as per specification (C3) seems to be most critical failure cause and overheating at gear mesh (C9) seems to be least critical failure cause. It is suggested to modify the current control practices as listed in Table 1 that failure causes (C3, C5, C10, C4, and C14) with large value of MCI should be kept under predictive maintenance, failure causes $(\mathrm{Cl} 3, \mathrm{C} 8, \mathrm{C} 7, \mathrm{Cl}$, and $\mathrm{C} 2)$ with moderate value of $\mathrm{MCI}$
TABLE 5: Scores for economic safety (ES).

\begin{tabular}{lc}
\hline Criteria for economic safety & Score \\
\hline Extremely low & 1 \\
Very low & 2 \\
Low & 3 \\
Fair & 4 \\
Average & 5 \\
Medium & 6 \\
Moderately high & 7 \\
High & 8 \\
Very high & 9 \\
Extremely high & 10 \\
\hline
\end{tabular}

TABLE 6: Scores for economic cost (EC).

\begin{tabular}{lc}
\hline Criteria for economic cost & Score \\
\hline Extremely low & 1 \\
Very low & 2 \\
Low & 3 \\
Fair & 4 \\
Average & 5 \\
Medium & 6 \\
Moderately high & 7 \\
High & 8 \\
Very high & 9 \\
Extremely high & 10 \\
\hline
\end{tabular}

should be kept under preventive maintenance, and failure causes (C12, C6, C11, and C9) with low MCI should be kept under corrective maintenance.

Moreover, it has been observed that almost 70\% down time is due to bearing failure and replacement practice is $100 \%$, so it is recommended to select standardized bearing with appropriate specifications and mount them properly during every replacement to avoid bearing misalignment (C5) and minimizing reverse and repeated cyclic loading; thus shaft fatigue (C14) and gear tooth fracture (C10) can be avoided. Appropriate condition monitoring is suggested to continuously record the condition of bearing damage and shaft damage to prevent sudden breakdown and starting thrust on these components. Also, the condition of lubricants should be checked and replaced whenever necessary rather than routine clean-up. Hence, sudden impact on the rolls (C5), design defects with bearing dimension/specification (C3), foreign matters/particles (C4), excessive overload and cyclic stresses $(\mathrm{C} 10)$, and reverse and repeated cyclic loading (C14) can be covered under recommendations. Failure causes with moderate and low MCI are controlled under preventive and corrective maintenance practices. Comparison matrix for deciding maintenance strategy is shown is Table 9.

\section{Conclusion and Scope}

This paper highlights multicriteria decision-making approach based on COPRAS-G to overcome the limitations of FMECA. 


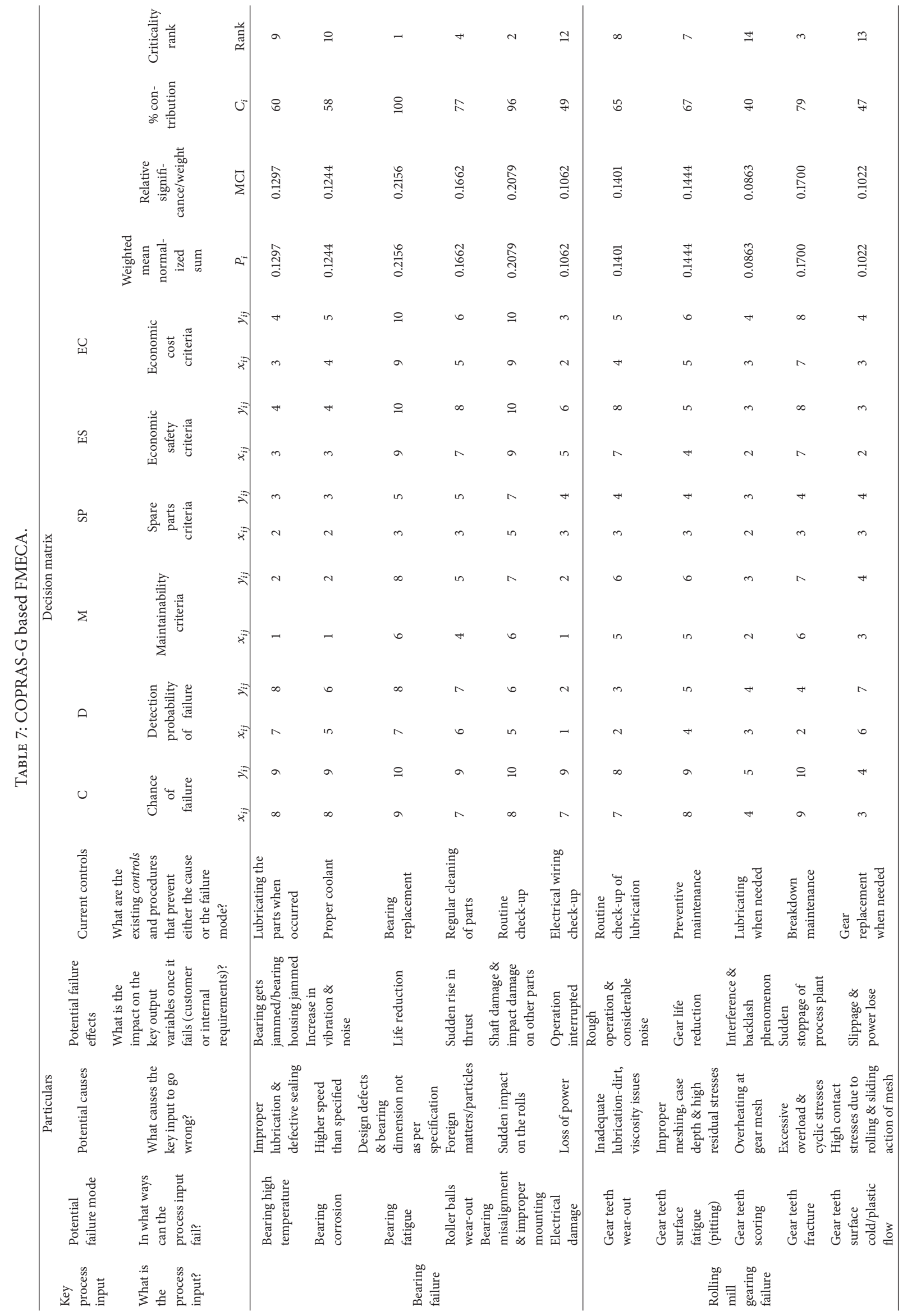




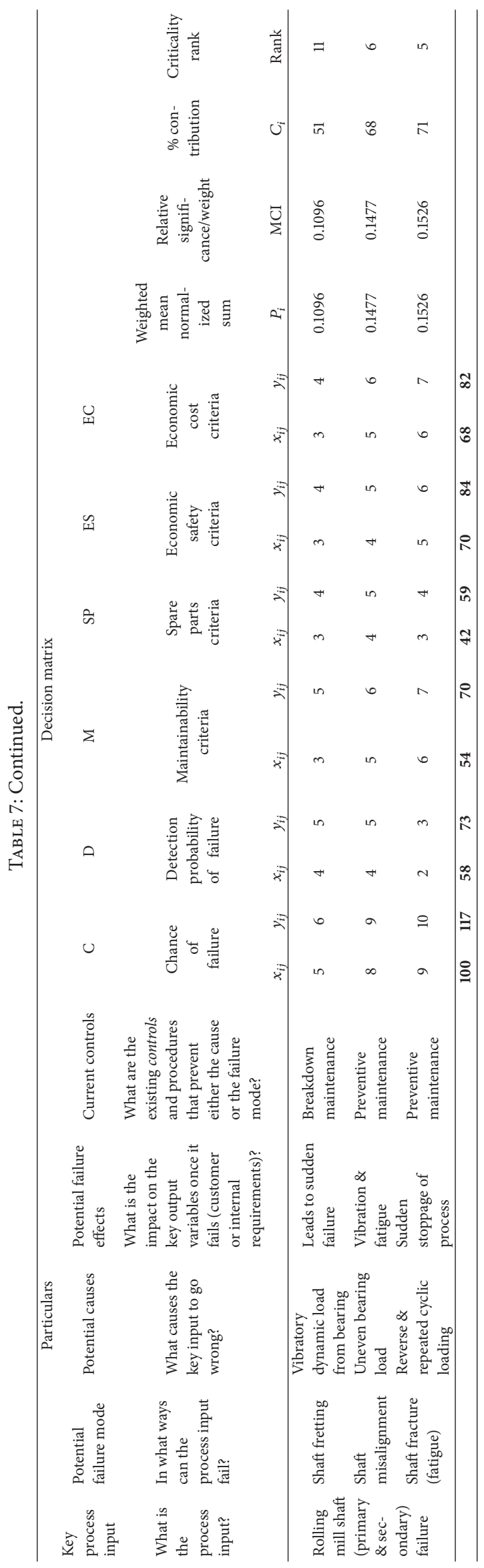


TABLE 8: Criticality ranking based on MCI.

\begin{tabular}{|c|c|c|c|c|c|}
\hline \multicolumn{2}{|l|}{ Failure cause versus criteria } & \multirow{2}{*}{$\begin{array}{l}\text { Weighted mean normalized sum } \\
\qquad P_{i}\end{array}$} & \multirow{2}{*}{$\begin{array}{c}\text { Relative weight } \\
\text { MCI }\end{array}$} & \multirow{2}{*}{$\begin{array}{c}\text { \% contribution } \\
C_{i}\end{array}$} & \multirow{2}{*}{$\begin{array}{c}\text { Criticality rank } \\
\text { Rank }\end{array}$} \\
\hline Failure cause & Notation & & & & \\
\hline Bearing high temperature & $\mathrm{C} 1$ & 0.1297 & 0.1297 & 60 & 9 \\
\hline Bearing corrosion & $\mathrm{C} 2$ & 0.1244 & 0.1244 & 58 & 10 \\
\hline Bearing fatigue & $\mathrm{C} 3$ & 0.2156 & 0.2156 & 100 & 1 \\
\hline Roller balls wear-out & $\mathrm{C} 4$ & 0.1662 & 0.1662 & 77 & 4 \\
\hline Bearing misalignment \& improper mounting & C5 & 0.2079 & 0.2079 & 96 & 2 \\
\hline Electrical damage & C6 & 0.1062 & 0.1062 & 49 & 12 \\
\hline Gear teeth wear-out & $\mathrm{C} 7$ & 0.1401 & 0.1401 & 65 & 8 \\
\hline Gear teeth surface fatigue (pitting) & $\mathrm{C} 8$ & 0.1444 & 0.1444 & 67 & 7 \\
\hline Gear teeth scoring & C9 & 0.0863 & 0.0863 & 40 & 14 \\
\hline Gear teeth fracture & $\mathrm{C} 10$ & 0.1700 & 0.1700 & 79 & 3 \\
\hline Gear teeth surface cold/plastic flow & $\mathrm{C} 11$ & 0.1022 & 0.1022 & 47 & 13 \\
\hline Shaft fretting & $\mathrm{C} 12$ & 0.1096 & 0.1096 & 51 & 11 \\
\hline Shaft misalignment & $\mathrm{C} 13$ & 0.1477 & 0.1477 & 68 & 6 \\
\hline Shaft fracture (fatigue) & $\mathrm{C} 14$ & 0.1526 & 0.1526 & 71 & 5 \\
\hline
\end{tabular}

TABLE 9: Comparison matrix for deciding maintenance strategy.

\begin{tabular}{lccc}
\hline Sr. number & Failure cause & Suggested maintenance strategy & Impact of MCI \& $\left(C_{i}\right)$ \\
\hline 1 & $\mathrm{C} 3, \mathrm{C} 5, \mathrm{C} 10, \mathrm{C} 4, \mathrm{C} 14$ & Predictive (condition based) maintenance & High MCI \& $\left(C_{i}\right)$ \\
2 & $\mathrm{C} 13, \mathrm{C} 8, \mathrm{C} 7, \mathrm{C} 1, \mathrm{C} 2$ & Preventive maintenance & Moderate MCI \& $\left(C_{i}\right)$ \\
3 & $\mathrm{C} 12, \mathrm{C} 6, \mathrm{C} 11, \mathrm{C} 9$ & Corrective maintenance & Low MCI \& $\left(C_{i}\right)$ \\
\hline
\end{tabular}

The case study presented in this paper shows how to deal with the problems encountered in aluminium wire rolling mill processing plant with mix of maintenance practices. It is concluded that the study will be helpful in deriving optimized maintenance plan to improve plant efficiency as a whole. The similar work can be extended for process industries of same or of different kinds in a view to decide suitable maintenance strategies in coordination with failure analysis.

\section{Competing Interests}

The authors declare that they have no competing interests.

\section{Acknowledgments}

The authors are thankful to Sampat Aluminium Pvt. Ltd., Ahmedabad, Gujarat, India, and its maintenance personnel, managers, and shop floor executives for giving them kind and valuable support in fulfillment of requirements directly or indirectly during this study.

\section{References}

[1] T. Sahoo, P. K. Sarkar, and A. K. Sarkar, "Maintenance optimization for critical equipments in process industry based on FMECA method," International Journal of Engineering and Innovative Technology, vol. 3, no. 10, pp. 107-112, 2014.

[2] W. Gilchrist, "Modeling failure modes and effects analysis," International Journal of Quality \& Reliability Management, vol. 10, pp. 16-23, 1993.
[3] M. Bevilacqua, M. Braglia, and R. Gabbrielli, "Monte Carlo simulation approach for a modified FMECA in a power plant," Quality and Reliability Engineering International, vol. 16, no. 4, pp. 313-324, 2000.

[4] M. Braglia, "MAFMA: multi-attribute failure mode analysis," International Journal of Quality \& Reliability Management, vol. 17, no. 9, pp. 1017-1033, 2000.

[5] S. Anish, D. Kumar, and P. Kumar, "Multi-factor failure mode criticality analysis using TOPSIS," Journal of Industrial Engineering, International, vol. 5, no. 8, pp. 1-9, 2009.

[6] M. Braglia, M. Frosolini, and R. Montanari, "Fuzzy TOPSIS approach for failure mode, effects and criticality analysis," Quality and Reliability Engineering International, vol. 19, no. 5, pp. 425-443, 2003.

[7] M. Braglia, M. Frosolini, and R. Montanari, "Fuzzy criticality assessment model for failure modes and effects analysis," International Journal of Quality \& Reliability Management, vol. 20, no. 4, pp. 503-524, 2003.

[8] K. Xu, L. C. Tang, M. Xie, S. L. Ho, and M. L. Zhu, "Fuzzy assessment of FMEA for engine systems," Reliability Engineering \& System Safety, vol. 75, no. 1, pp. 17-29, 2002.

[9] H. Gargama and S. K. Chaturvedi, "Criticality assessment models for failure mode effects and criticality analysis using fuzzy logic," IEEE Transactions on Reliability, vol. 60, no. 1, pp. 102-110, 2011.

[10] D. D. Adhikary, G. K. Bose, D. Bose, and S. Mitra, "Multi criteria FMECA for coal-fired thermal power plants using COPRAS-G," International Journal of Quality \& Reliability Management, vol. 31, no. 5, pp. 601-614, 2014.

[11] F. Zhang, "Failure modes and effects analysis based on fuzzy TOPSIS," in Proceedings of the IEEE International Conference 
on Grey System and Intelligent Services (GSIS), pp. 588-593, Leicester, UK, 2015.

[12] N. Chanamool and T. Naenna, "Fuzzy FMEA application to improve decision-making process in an emergency department," Applied Soft Computing, vol. 43, pp. 441-453, 2016.

[13] H.-C. Liu, J.-X. You, X.-Y. You, and M.-M. Shan, "A novel approach for failure mode and effects analysis using combination weighting and fuzzy VIKOR method," Applied Soft Computing, vol. 28, pp. 579-588, 2015.

[14] J. L. Deng, "Introduction to grey system theory," The Journal of Grey Theory, vol. 1, no. 1, pp. 1-24, 1989.

[15] E. K. Zavadskas, A. Kaklauskas, Z. Turskis, and J. Tamošaitiene, "Selection of the effective dwelling house walls by applying attributes values determined at intervals," Journal of Civil Engineering and Management, vol. 14, no. 2, pp. 85-93, 2008.

[16] E. K. Zavadskas, A. Kaklauskas, Z. Turskis, and J. Tamosaitiene, "Multi attribute decision making model by applying grey numbers," Informatica, vol. 20, no. 2, pp. 305-320, 2009.

[17] S. R. Maity, P. Chatterjee, and S. Chakraborty, "Cutting tool material selection using grey complex proportional assessment method," Materials and Design, vol. 36, pp. 372-378, 2012.

[18] C.-L. Chang, C.-C. Wei, and Y.-H. Lee, "Failure mode and effects analysis using fuzzy method and grey theory," Kybernetes, vol. 28, no. 9, pp. 1072-1080, 1999.

[19] Y.-H. Lin, P.-C. Lee, and H.-I. Ting, "Dynamic multi-attribute decision making model with grey number evaluations," Expert Systems with Applications, vol. 35, no. 4, pp. 1638-1644, 2008.

[20] C. L. Hwang and K. Yoon, Multiple Attribute Decision Making: Methods and Applications, vol. 186 of Lecture Notes in Economics and Mathematical Systems, Springer, New York, NY, USA, 1981. 


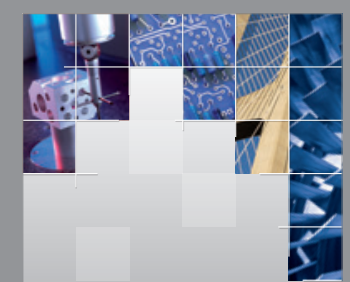

\section{Enfincering}
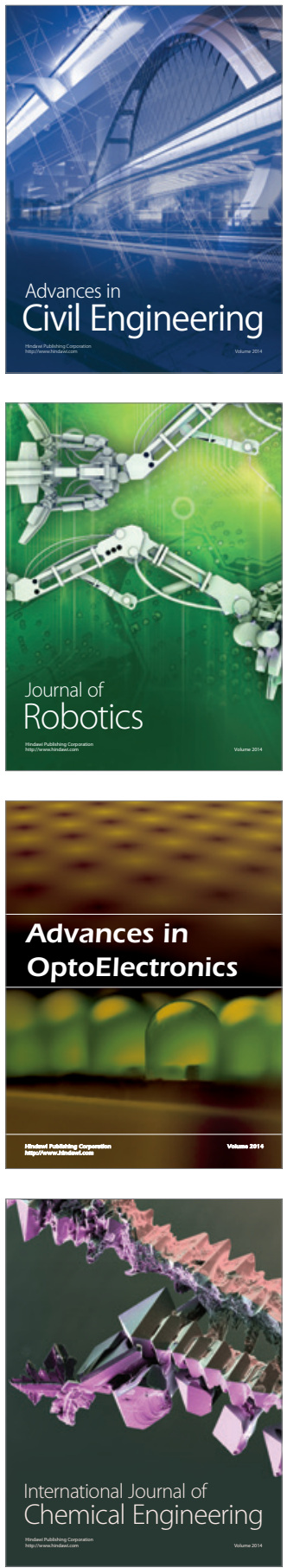

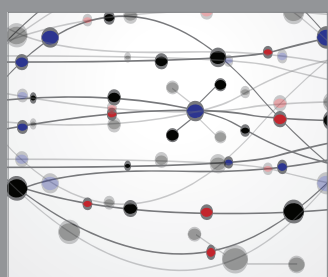

The Scientific World Journal

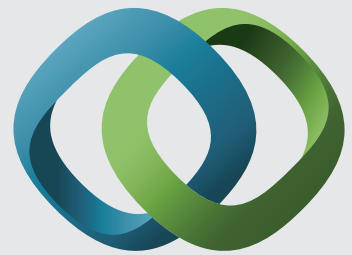

\section{Hindawi}

Submit your manuscripts at

http://www.hindawi.com
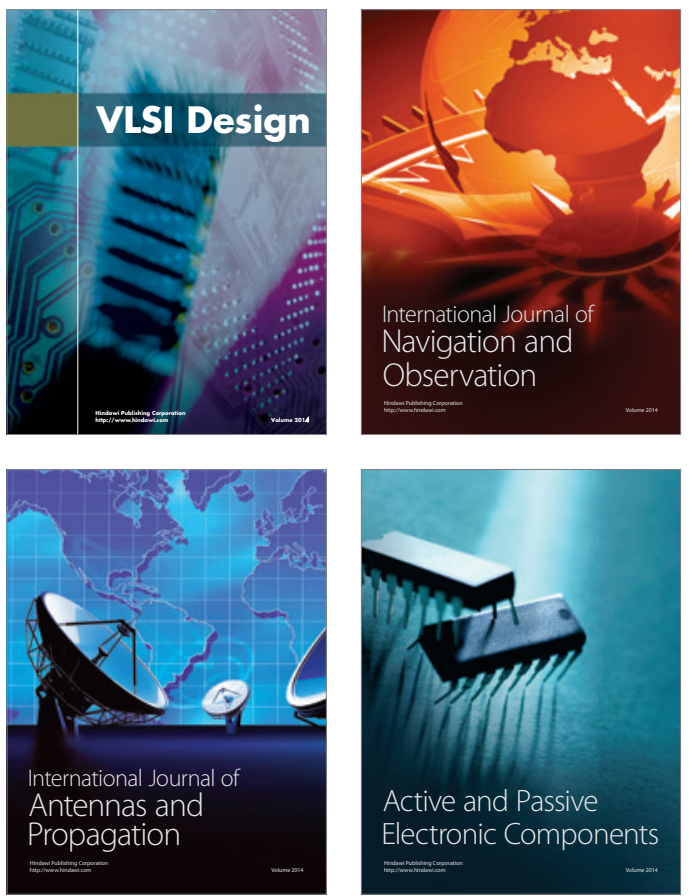
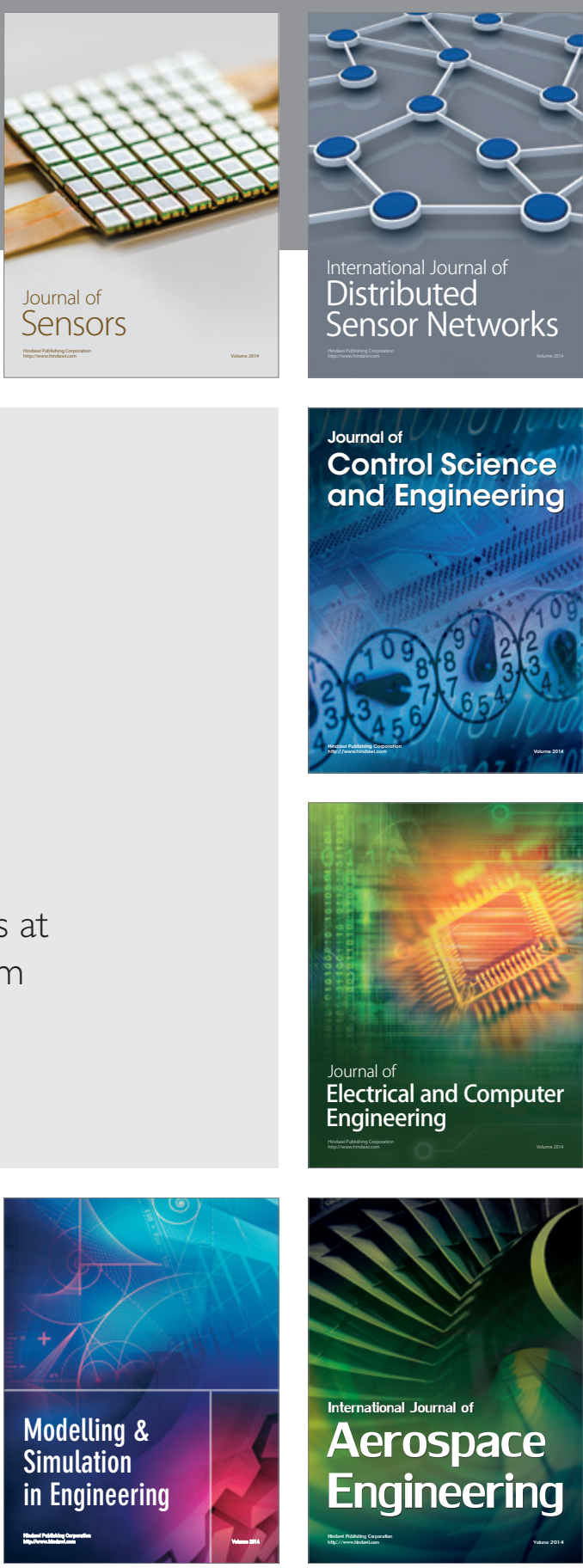

International Journal of

Distributed

Sensor Networks

Journal of

Control Science

and Engineering
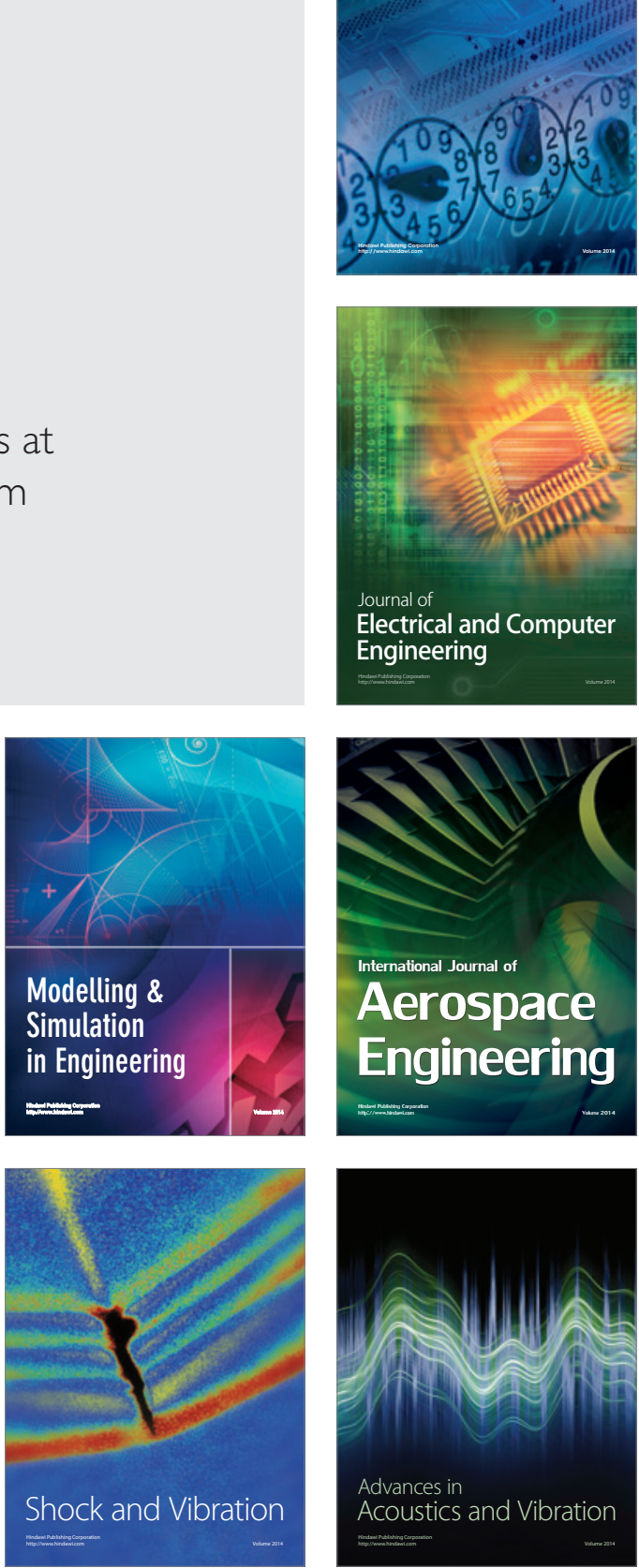